\title{
Torsion of a splenule
}

\author{
Mustafa Gok • S. Pinar Karakas
}

Received: 30 May 2010 /Revised: 20 July 2010 / Accepted: 16 August 2010 /Published online: 18 September 2010

(C) Springer-Verlag 2010

A 14-year-old boy presented with nausea and left-sided abdominal pain of 2 days' duration and had elevated white blood cells. Abdominal CT with contrast agent shows a $4 \times$ $4 \times 3.7-\mathrm{cm}$ well-defined, hypodense structure in the splenic hilum with surrounding fat stranding and free fluid (Fig. 1). It was not a simple cyst and did not show significant enhancement. Differential diagnoses included complicated pancreatic pseudocyst, mesenteric cyst and torsion of a splenule. US displays the lesion as a solid structure with identical echogenicity to the spleen without blood flow (Fig. 2). Diagnosis of torsion of a splenule was made; the splenule was later removed.

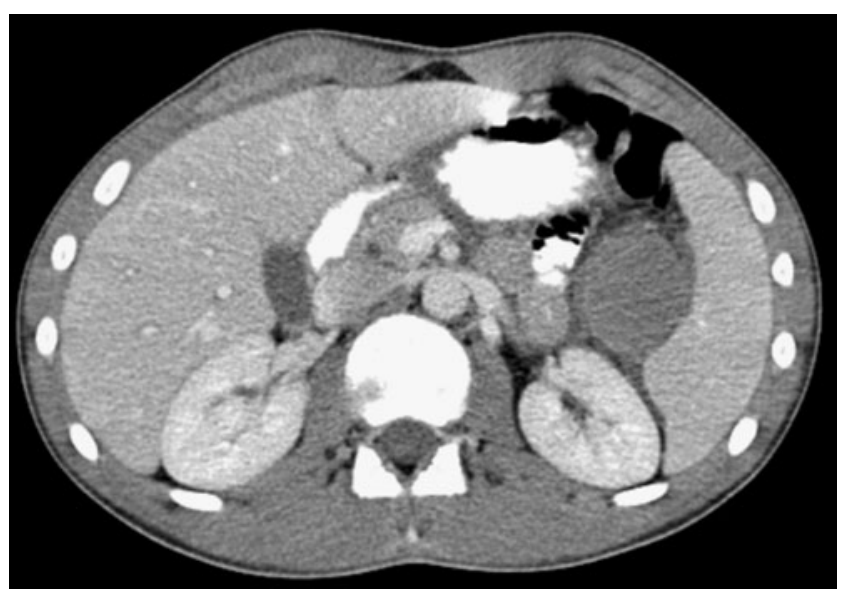

Fig. 1 Abdominal CT with contrast agent

M. Gok $\cdot$ S. P. Karakas $(\bowtie)$

Pediatric Radiology, Cleveland Clinic,

Cleveland, OH 44195, USA

e-mail: karakap@ccf.org

\section{Gok}

Department of Radiology, Celal Bayar University,

Manisa, Turkey

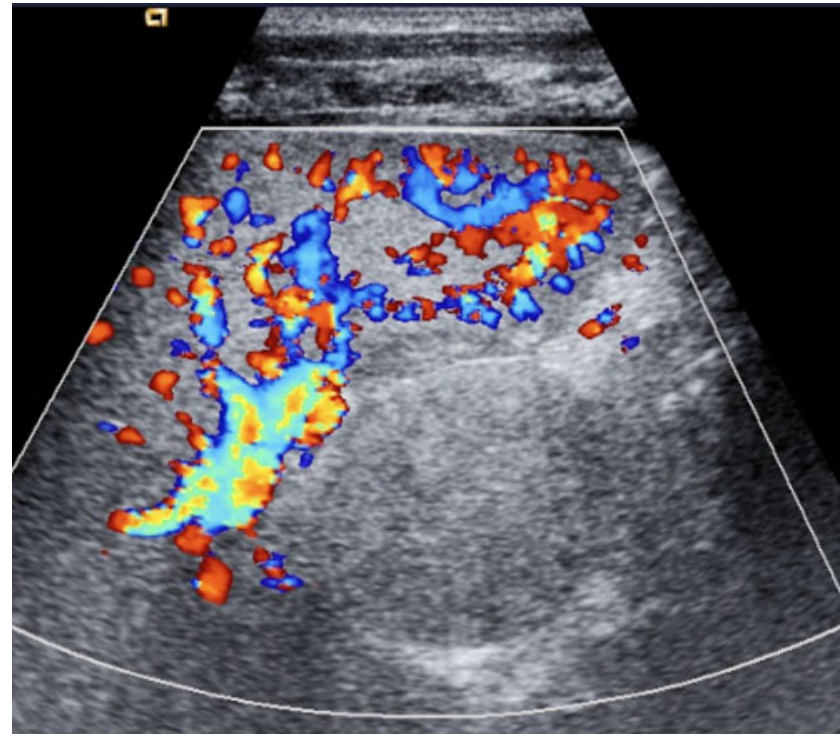

Fig. 2 Abdominal US with color Doppler

Ectopic splenic tissue is a common anomaly $(10-30 \%$ of autopsies). Failed fusion of mesenchymal splenic buds results in splenules in the left side of the abdomen, usually in the splenic hilum (75\%) [1, 2]. Torsion of a splenule is rare and imaging is usually inconclusive but an early US exam can prove the diagnosis, showing identical echo to the spleen and absence of blood flow before necrosis develops.

\section{References}

1. Impellizzeri P, Montalto AS, Borruto FA et al (2009) Accessory spleen torsion: rare cause of acute abdomen in children and review of literature. Pediatr Surg 44:e15-e18

2. Perèz Fontàn FJ, Soler R, Santos M et al (2001) Accessory spleen torsion: US, CT and MR findings. Eur Radiol 11:509-512 